\title{
Civil Servants' Internet Skills: Are They Ready for E-Government?
}

\author{
Alexander van Deursen and Jan van Dijk \\ University of Twente, Department of Media, Communication and Organization, \\ P.O. Box 217, 7500 AE Enschede, The Netherlands \\ a.j.a.m.vandeursen@utwente.nl
}

\begin{abstract}
In order to utilize the possibilities of information and communication technology within the public domain and thereby further develop the electronic government, it is necessary that civil servants possess sufficient levels of Internet skills. Higher levels of these skills among professionals in the public sphere might result in better Internet usage, thus improving both productivity and efficiency. Based on results of this research, we can conclude that the levels of operational and formal Internet skills are higher than the levels of information and strategic Internet skills. A main finding is that civil servants do not perform well on higher Internet skills involving information and strategic tasks. The implications of the results are discussed and several policy recommendations to improve digital skill levels of civil servants are given.
\end{abstract}

Keywords: Internet skills, civil servants, productivity, efficiency.

\section{Introduction}

In 2007 and 2008, two large scale studies were conducted at the University of Twente to test the level of Internet skills of Dutch citizens [1,2]. To measure these skills, a sequential definition was used accounting both for medium- and content-related Internet skills. The results indicate that the level of Internet skills varies largely between different segments of the Dutch population, and that low levels of these skills hinder an optimal use of the possibilities offered by the Internet. In order to utilize the possibilities of the Internet within the public domain and thereby further develop the electronic government, it is necessary that civil servants possess sufficient levels of Internet skills. Not much is known about the current levels of these skills among public servants. The training of civil servants in basic ICT skills has been identified as a major problem in the development of e-Government [3]. In his Ceremonial speech of CommunicAsia 2000, the Prime Minister mentioned: "We will equip our public servants with the necessary skills, tools, systems and infrastructure to make them effective workers in the digital economy. Indeed, when the world is marching to Internet speed, our public servants must be able to work at a similar speed or be left behind."

The Internet plays an important role, both for civil servants that are in contact with citizens through the Internet or for servants that are responsible for current and future developments. Based on the results of the two studies conducted among Dutch 
citizens, one might question whether civil servants possess the necessary Internet skills. Even though they may be in contact with public electronic services on a daily basis, they might not perform better than ordinary Dutch citizens. In this study, the actual level of Internet skills among different segments of civil servants (including executive employees, policy advisors and administrators) is measured in performance tests. The measured Internet skills are discussed in Section 2. Then, Section 3 describes the method applied, followed by an overview of the findings in Section 4. Section 5 contains the conclusions and policy recommendations.

\section{Research Background}

The literature concerning Internet skills is not consistent in the terms used and in the underlying concepts applied. The confusion caused by the varied terminologies and meanings might be the cause for a lack of practical implementations and support for all these terms [1]. The development of assessments is hampered particularly by the lack of consensus on what constitutes measurable dimensions [2]. Operational definitions have rarely been defined and most of the Internet skills research applies limited definitions that do not extend beyond so-called 'button knowledge,' not paying attention to the multiple underlying indices. This stipulates the need for more academic research. To encourage research to focus on in-depth skill measurement, Van Deursen \& Van Dijk [3,4] elaborated four types of Internet skills. The four Internet skills categories proposed are based on individual abilities. So far, most conducted studies strongly focused on the operation and use of computers and the Internet. Van Deursen \& Van Dijk [3,4] proposed the following set of Internet skills:

Operational skills means being able to:

- Operate an Internet browser:

- Opening websites by entering the URL in the browser's location bar

- Surfing forward and backward between pages using the browser buttons

- Saving files on the Hard Disk

- Opening various common file formats (e.g., PDF, SWF)

○ Bookmarking websites

- Changing the browser's preferences (e.g., start page)

- Operate online search engines:

$\circ$ Entering keywords in the proper field

- Executing the search operation

- Opening search results in the search result lists

- Complete online forms:

○ Using the different types of fields and buttons (e.g., dropdown menus)

- Submitting a form 
Formal skills means being able to:

- Navigate the Internet by:

○ Recognizing and using hyperlinks (e.g., menu links, textual links, and image links) in different menu and website layouts

- Maintain a sense of location while navigating the Internet, meaning:

o Not getting disoriented when surfing within a website

o Not getting disoriented when surfing between websites

$\circ \quad$ Not getting disoriented when browsing through, and opening search results

Information skills means being able to

- Locate required information, by:

- Choosing a search system or place to seek information

- Defining search queries that focus on the information problem

- Selecting information

○ Evaluating information sources

Strategic skills means being able to:

- Take advantage of the Internet by:

- An orientation towards a particular goal

○ Taking the right action to reach this goal

- Making the right decision to reach this goal

o Gaining the benefits associated with this goal

This definition was used in the Internet skills studies among Dutch citizens, in which subjects had to complete assignments on the Internet. Using performance tests for measuring Internet skills is much more reliable and valid than using surveys in which subjects are asked to assess their own level of skills [5,6]. In most cases, studies that use surveys provide an exaggerated picture of the actual Internet skill levels. This problem is compounded by the fact that Internet skills, in most cases, are measured very superficially and do not go beyond operational skills. This causes surveys to generate a too flattering picture compared to the actual skill levels. Results of both studies revealed that operational and formal Internet skills were not the most problematic. Rather, information and strategic Internet skills presented the greatest difficulties. The results also revealed that Internet experience only correlated to the level of operational skills, and that older age groups did not perform worse than their younger counterparts with regards to information and strategic skills. As such, the assumption that there would not be a digital skill problem without the presence of an elderly population was tempered.

One might suggest that high levels of information and strategic skills are a necessity for administrators and policy advisors. These skills form part of their ability to define policy and administer the electronic government. For executive employees, high levels of operational and formal skills are a necessity, as they have to work with online applications. Indeed, citizens who have trouble with online public services expect support. Higher levels of Internet skills among professionals in the public 
sphere might result in better Internet usage, thus improving both productivity and efficiency. Also, one might expect positive effects in public service delivery. The problems described and the proposed definition lead to the first research question:

$R Q$ 1: What are the levels of operational, formal, information, and strategic Internet skills of Dutch civil servants?

To gain a better understanding of the levels of these skills among civil servants, they can be compared to the Internet skill levels of citizens. Other studies that measure Internet skills more profoundly are very rare. It is expected that Internet skills will not be the same among different segments of civil servants. This study distinguishes among two groups of civil servants. On the on hand:

- Administrators that are responsible for political and administrative affairs and for the institution of the public information supply, both internally and externally. They have to decide on the acquisition and implementation of infrastructures, architectures and applications and assess whether these fit within the existing organization or whether they need to be adapted. It is therefore recommended that administrators possess more strategic ICT knowledge and skills.

- $\quad$ Policy advisors in the field of eGovernment that support administrators in decision-making. Policy advisors have to be aware of all possibilities that ICT usage offers to the government.

On the other hand:

- $\quad$ Executive employees that use electronic applications for serving citizens. They need to be able to operate applications for handling forms and transactions. And need sufficient operational and formal skills as well as specific information skills associated with their positions.

Besides these groups of civil servants, gender, education, and age are accounted for, as are Internet experience, amount of time spent on the Internet, using social support, the primary location of Internet use, and socio-economic status, all factors that come forward as an explanation of Internet usage differences $[7,8,9,10]$. The assumption that Internet skills will not be the same among different segments of civil servants leads to the second research question:

$R Q$ 2: Are there significant differences among groups of civil servants and categories of gender, age, educational level attained, Internet experience, amount of time spent weekly on the Internet, help from peers and the primary location of Internet use?

If answers to these questions reveal that the levels of particular Internet skills among civil servants is not adequate in comparison to their job requirements, the following research question then needs to be answered:

$R Q$ 3: How can the level of Internet skills among (particular groups of) civil servants be increased? 


\section{Method}

\subsection{Subjects}

During a time period of six months, 98 civil servants were visited and subjected to performance tests. The participating civil servants were selected at departments within executive policy agencies and municipalities that have the most direct contact with citizens. The departments of Social Affairs and Public affairs were selected in the municipalities. Municipalities were randomly selected throughout the Netherlands and their size was taken into account in order to reflect the national distribution in the Netherlands. The heads of the selected departments received a letter signed by the Ministry of Internal Affairs (the sponsor of the study), in which they were invited to take part in a study. The procedure was also explained in the letter. Municipalities that agreed to participate randomly selected six civil servants: three in the Social Affairs department and three in the Public Affairs department. In every department, two executive employees that had direct contact with citizens and one administrator responsible for electronic service delivery were selected. At the executive policy agencies, three administrators and five executing employees were selected. The characteristics of the subjects are summarized in Table 1.The average years of age was $45(\mathrm{SD}=8.7)$, average years of Internet experience was 9.0 years $(\mathrm{SD}=4.2)$, and the average amount of hours spent online weekly 9.0 ( $\mathrm{SD}=13.2)$.

Executive employees were civil servants that had direct contact with citizens, mainly at the counter. The administrators in most cases fulfilled a management position in the department of Social Affairs or Public Affairs. Some were the head of a section that contained more departments. Policy advisors all had positions in where they directly advised the managers. All subjects directly used the Internet, either at the counter, for defining policy or for advising in the development of electronic services.

Table 1. Sample characteristics of participating civil servants

\begin{tabular}{|c|c|c|}
\hline & $\mathbf{n}$ & $\%$ \\
\hline \multicolumn{3}{|l|}{ Position } \\
\hline Executing position & 50 & 51 \\
\hline Administrator & 31 & 32 \\
\hline Policy / Advise position & 17 & 17 \\
\hline \multicolumn{3}{|l|}{ Organization } \\
\hline Municipalities & 78 & 80 \\
\hline Public Affairs & 40 & 51 \\
\hline Social Affairs & 35 & 45 \\
\hline Other & 3 & 4 \\
\hline Executive Policy Agencies & 20 & 20 \\
\hline \multicolumn{3}{|l|}{ Education } \\
\hline Low & 15 & 15 \\
\hline Middle & 30 & 31 \\
\hline High & 53 & 54 \\
\hline \multicolumn{3}{|l|}{ Age } \\
\hline $18-29$ & 6 & 6 \\
\hline $30-39$ & 20 & 20 \\
\hline $40-54$ & 59 & 60 \\
\hline $55-80$ & 13 & 13 \\
\hline \multicolumn{3}{|l|}{ Gender } \\
\hline Male & 40 & 41 \\
\hline Female & 58 & 59 \\
\hline
\end{tabular}




\subsection{Technical Specifications}

The studies were conducted in the subject's office. For the performance test, a laptop with separate keyboard and mouse was used. The laptop connected to the Internet on a high-speed wireless network. During the study, subjects were allowed to use their choice of browser (Internet Explorer 6, 7 or Mozilla Firefox 3), so that they could replicate their usual Internet use. No default page was set on the browsers and all the assignments started out with an empty page. To ensure that subjects were not influenced by previous users' actions, the browser was totally reset after each session.

\subsection{Performance Test Assignments}

Eight assignments were prepared, two for measuring operational Internet skills, two for formal Internet skills, two for information Internet skills and two for strategic Internet skills. The assignments were a combination of the assignments used in the two Internet skills studies conducted among Dutch citizens. Some assignments, however, were shortened in order to lower the barrier to participation. A complete session took about one-and-a-half hours.

In the two operational skills assignments, subjects were for example instructed to open and save a PDF file, add a website to the Favorites (or bookmarks), fill out a form, and use a search engine. The two formal Internet skill assignments instructed subjects to look up simple contact details at two governmental agencies that used totally different website layouts and menu structures. Subjects were also asked to follow multiple links, go back to the homepages of websites that were opened in different windows, and inspect different search results after conducting a search operation. The first of the two information skills assignments asked subjects to look up subscription information at the website of a major telecom provider. In the second assignment, a more open search task was given using Google as a departure point: subjects had to look up information regarding minimum wages. The first strategic skills assignment was a follow-up that asked subjects what they would do after being underpaid. In the final strategic skills assignment, subjects were instructed to book a flight-hotel combination that was as inexpensive as possible, accounting for few demands. The appendix contains the full list of the eight assignments that subjects were asked to complete. All assignments were of a closed format (i.e., only one answer or action was correct).

The subjects' performance was measured by their successful completion of assignments and the time (in seconds) they spent on each assignment. Both completion and time required were noted directly. In all of the assignments, the subjects themselves decided when they were finished or wanted to give up. After a specific, ample time period, a deadline appeared when the test leader gently asked the subjects to pass on to the next assignment. However, no encouragements were given, as the pressure to succeed was already higher in a test setting. All subjects completed the assignments in the same order.

Prior to the experiment, a five minute questionnaire was administered to gather personal data such as position within the department, age, gender, education level, Internet experience and information about the frequency and location of the subjects' regular Internet usage. 


\section{Results}

This section starts with a general overview of the completion of the assignment. Subsequently, linear regression analyses are performed for both the number of tasks completed and the time spent on the tasks for each skill in order to identify factors that might influence the level of Internet skills.

\subsection{General Overview}

The two assignments used to measure operational Internet skills consisted of seven tasks. According to Table 2, the subjects completed an average of $74 \%$ of these tasks. The two assignments used to measure formal Internet skills consisted of three tasks, of which the subjects completed an average of $80 \%$. Of the two information Internet skills assignments, an average of $50 \%$ was completed. Finally, of the two strategic Internet skill assignments, an average of $30 \%$ was completed. The time spent on the assignments differed substantially as depicted in Table 2. Of the seven operational Internet skill tasks, only $14 \%$ of civil servants were able to complete all of them successfully. 58 Percent of the civil servants were able to successfully complete all three formal skill tasks, $30 \%$ both the information skill assignments and only $9 \%$ both of the strategic skill assignments.

Table 2. Average number of tasks completed successfully and average time spend on the tasks

\begin{tabular}{lcccc}
\hline & \multicolumn{2}{c}{ Average \# of tasks completed } & \multicolumn{2}{c}{ Time spent on tasks (seconds) } \\
\cline { 2 - 5 } & M (SD) & \% & M (SD) & Min. / Max. \\
\hline Operational tasks (7) & $5.2(1.2)$ & 74 & $314(108)$ & $97 / 631$ \\
Formal tasks (3) & $2.4(0.7)$ & 80 & $353(131)$ & $118 / 872$ \\
Information tasks (3) & $1.0(0.8)$ & 50 & $518(238)$ & $155 / 1200^{*}$ \\
Strategic tasks (2) & $0.6(0.7)$ & 30 & $1242(486)$ & $216 / 2400^{*}$ \\
\hline *
\end{tabular}

*Maximum time allowed

\subsection{Operational Internet Skills}

Table 3. Linear regression results for the \# of operational tasks completed successfully and time spent

\begin{tabular}{lrrrr}
\hline & \multicolumn{2}{c}{$\begin{array}{c}\text { Number of Tasks } \\
\text { completed successfully }\end{array}$} & \multicolumn{2}{c}{ Time spent } \\
\hline Gender & $\boldsymbol{t}$ & $\boldsymbol{\beta}$ & $\boldsymbol{t}$ & $\boldsymbol{\beta}$ \\
Age & -.672 & -.069 & -.078 & -.007 \\
Education (low/middle/high) & -4.035 & $-.391 * * *$ & 5.098 & $.463^{* * *}$ \\
Internet experience (years) & -1.841 & -.215 & .488 & .054 \\
Internet use (hours a week)) & .490 & .047 & -.736 & -.067 \\
Position (admin. and policy adv./executive) & 1.429 & .139 & -1.316 & -.121 \\
Participated in an Internet course (yes/no) & -3.032 & $-.343^{* * *}$ & 2.162 & $.231^{*}$ \\
Receive help from others (yes/no) & -.241 & -.023 & 1.405 & .126 \\
Location (at home/elsewhere) & -1.890 & -.191 & 2.125 & $.200^{*}$ \\
\hline Adjusted $\mathrm{R}^{2}$ & -.070 & -.006 & .278 & .024 \\
$F$ & & .29 & .39 \\
$* p<.05 * * * p<001 . \mathrm{N}=98$ & & $4.46^{* * *}$ & & $6.15^{* * *}$ \\
\hline
\end{tabular}

$* p<.05, * * * p<.001 . \mathrm{N}=98$ 
As shown in Table 3, age and position are the main predictors for the level of operational Internet skills. They are significant both for the number of tasks completed successfully and the time spent on the tasks. Administrators and policy advisors perform better than executive employees. Receiving help from others was a minor contributor to the time spent on Internet tasks.

\subsection{Formal Internet Skills}

The two assignments for measuring formal Internet skills consisted of three tasks, of which an average of 2.5 was completed successfully. As presented in Table 4, age and position once again are the main contributors for the number of formal tasks completed successfully and for the amount of time spent on the tasks. Also here administrators and policy advisors perform better than executive employees.

Table 4. Linear regression results for the \# of formal tasks completed successfully and time spent

\begin{tabular}{|c|c|c|c|c|}
\hline & \multicolumn{2}{|c|}{$\begin{array}{c}\text { Number of Tasks } \\
\text { completed successfully }\end{array}$} & \multicolumn{2}{|c|}{ Time spent } \\
\hline & $t$ & $\boldsymbol{\beta}$ & $t$ & $\boldsymbol{\beta}$ \\
\hline Gender & ,908 & 101 & ,167 & ,018 \\
\hline Age & $-2,581$ &,$- 273 * * *$ & 3,280 &, $344 * * *$ \\
\hline Education (low/middle/high) & $-1,420$ &,- 181 &,- 472 &,- 060 \\
\hline Internet experience (years) & 1,593 & 168 & 1,074 &, 113 \\
\hline Internet use (hours a week)) & ,245 & ,026 &,- 726 &,- 077 \\
\hline Position (administrator/executive) & $-2,153$ &,$- 266 *$ & 1,250 &, 153 \\
\hline Participated in an Internet course (yes/no) & $-1,148$ &,- 117 & $-1,275$ &,- 131 \\
\hline Receive help from others (yes/no) & 268 & ,029 & 1,029 & ,112 \\
\hline Location (at home/elsewhere) &,- 928 &,- 093 &, 725 & 072 \\
\hline Adjusted $\mathrm{R}^{2}$ & & .16 & & .19 \\
\hline$F$ & & $1.89 *$ & & $2.22 *$ \\
\hline
\end{tabular}

$* p<.05, * * * p<.001, \mathrm{~N}=98$

\subsection{Information Internet Skills}

Table 5. Linear regression results for the \# of information tasks completed successfully and time spent

\begin{tabular}{lrrrr}
\hline & \multicolumn{2}{c}{$\begin{array}{c}\text { Number of Tasks } \\
\text { completed successfully }\end{array}$} & \multicolumn{2}{c}{ Time spent } \\
\hline Gender & $\boldsymbol{t}$ & $\boldsymbol{\beta}$ & $\boldsymbol{t}$ & $\boldsymbol{\beta}$ \\
Age & -0.36 & -.04 & 2.06 & $.23^{*}$ \\
Education (low/middle/high) & -1.62 & -.17 & 1.40 & .15 \\
Internet experience (years) & 1.60 & .20 & -0.70 & -.09 \\
Internet use (hours a week)) & 0.15 & .02 & 0.25 & .03 \\
Position (admin. and policy adv./executive) & 1.99 & .21 & -1.40 & -.15 \\
Participated in an Internet course (yes/no) & -0.64 & -.08 & 1.12 & .14 \\
Receive help from others (yes/no) & -0.67 & -.07 & -0.32 & -.03 \\
Location (at home/elsewhere) & -0.06 & -.06 & 0.76 & .08 \\
\hline Adjusted ${ }^{2}$ & 0.02 & .02 & 0.44 & .04 \\
$F$ & & .12 & & .12 \\
$* p<.05, \mathrm{~N}=98$ & & $2.48^{*}$ & & $2.37^{*}$ \\
\hline F & & & &
\end{tabular}


The selection of civil servants was mainly based on their position and department. We did not apply a quota sample for gender, age, and education, which would have made it much harder to find willing civil servants to participate. The drawback, however, is that differences among these groups do not vary greatly. As a result, there are no significant predictors indicated in the regression analyses, as shown in Table 5.

\subsection{Strategic Internet Skills}

Of the two strategic skill assignments, subjects completed an average of 0.6 assignments. Just like the regression analyses in the prior section, no significant contributors appear, as can be seen from Table 6 .

Table 6. Linear regression results for the \# of strategic tasks completed successfully and time spent

\begin{tabular}{lrrrr}
\hline & $\begin{array}{c}\text { Number of Tasks } \\
\text { completed successfully }\end{array}$ & \multicolumn{2}{c}{ Time spent } \\
\hline & $\boldsymbol{t}$ & $\boldsymbol{\beta}$ & $\boldsymbol{t}$ & $\boldsymbol{\beta}$ \\
\hline Gender & 1.38 & .15 & 2.53 & .29 \\
Age & -1.77 & -.18 & -1.00 & -.11 \\
Education (low/middle/high) & 1.01 & .13 & -0.51 & -.07 \\
Internet experience (years) & 0.52 & .05 & 0.51 & .06 \\
Internet use (hours a week)) & 0.82 & .09 & 0.70 & .08 \\
Position (admin. and policy adv./executive) & 0.34 & .04 & -0.90 & -.12 \\
Participated in an Internet course (yes/no) & -2.51 & -.25 & 0.74 & .08 \\
Receive help from others (yes/no) & -1.31 & -.14 & -1.73 & -.20 \\
Location (at home/elsewhere) & 0.13 & .01 & -1.23 & -.13 \\
\hline Adjusted $\mathrm{R}^{2}$ & & .12 & & .14 \\
$F$ & & $2.41 *$ & & $2.33^{*}$ \\
\hline${ }^{*} p<.05, \mathrm{~N}=98$ & & & &
\end{tabular}

\section{Conclusions and Policy Recommendations}

The in this study measured Internet skills should be considered as basic skills that civil servants need in order to work for the electronic government. One might even suggest these skills as a minimum norm, which is also desired for citizens that want to function in contemporary information-based society [11]. Further still, this study did not take into account the wide array of extended ICT knowledge and skills that exists and that is necessary for specific positions. Based on results of this research, we can conclude that the levels of operational and formal Internet skills are higher than the levels of information and strategic Internet skills. The operational and formal Internet skills are not the most problematic; these are the information and strategic Internet skills of which on average not even half of the assignments were completed successfully.

In order to determine whether there are statistically significant differences among gender, age, educational level attained, position (administrator, policy advisor, or executive employee), Internet experience, amount of Internet use, following an Internet course and obtaining help from others, the study took all of these variables into account in regression analyses. The results indicated that age and position 
appear most important for the civil servant's level of operational and formal Internet skills. Younger civil servants performed better than their older counterparts, and the executive employees performed worse than policy advisors and administrators. With regards to the level of strategic skills, it is harder to point out contributing factors.

The main question that arises from these conclusions is whether the state of affairs hinders further development of the electronic government. As outlined in the first section, the Internet plays an important role for civil servants that are in direct contact with citizens through the Internet or are responsible for current and future developments. All civil servants would benefit from better information and strategic Internet skills. Information skills consisting of selecting search systems, formulating search queries, and selecting and evaluating information sources are necessary in an increasing number of governmental positions and especially among policy advisors. Making use of strategic skills in government positions involves using information as a means in specific services and positions, including information provision, transactions, maintaining contacts, and developing organizational strategies. For executive employees, high levels of operational and formal skills are a necessity, as they have to work with online applications for handling forms and transactions. They also need specific information skills associated with their positions. When these skills are not adequate, more training, or even replacement of the employee, is necessary. Indeed, citizens who have trouble with online public services expect support. According to the results of this research, one might question whether civil servants are able to provide such assistance.

Sufficient levels of Information and strategic Internet skills are important for administrators and policy advisors to form part of their ability to define policy and administer the electronic government. Administrators are responsible for the institution of the public information supply, both internally and externally. They have to decide on the acquisition and implementation of infrastructures, architectures and applications and assess whether these fit within the existing organization or whether they need to be adapted. It is therefore recommended that administrators possess more Internet skills. Policy advisors should support administrators in decision-making and have to be aware of all possibilities that the Internet offers to the government.

It is highly recommended to improve the levels of Internet skills among civil servants, especially the levels of information and strategic Internet skills. It must be stressed that the government is the primary party responsible for the development and possession of these skills among its civil servants. Employers often expect that their employees possess general ICT competency that was learned either at the home or at the school. As such, they assume that employees only need specific training. For instance, more educated employees are expected to possess all necessary Internet skills, which they are not tested for. Civil servants have difficulties using search engines effectively. Knowledge regarding online exchange and cooperation with other companies and citizens is not covered in training programs. It is recommended that the Internet skill levels are tested when hiring new employers, preferably using tests or surveys.

Executive employees should be partly educated in operational and formal Internet skills, just as older administrators and policy advisors. Specific computer courses 
neglect some elementary operational and formal skills by having too narrow a focus. Executive employees cannot help insufficiently skilled citizens if they themselves only possess elementary knowledge. Administrators and some policy advisors would benefit from training in strategic information management, which is all too often passed to the ICT department. Currently, administrators follow several training programs that neglect information management and focus on financial and juridical affairs or human resource management [12]. Policy advisors would benefit from taking part in training programs for information skills and strategic skills.

\section{References}

1. Bawden, D.: Information and Digital Literacies: A Review of Concepts. Journal of Documentation 57(2), 218-259 (2001)

2. Ba, H., Tally, W., Tsikalas, K.: Investigating children's emerging digital literacies. Journal of Technology, Learning and Assessment 1(4), 1-48 (2002)

3. Van Deursen, A.J.A.M., Van Dijk, J.A.G.M.: Measuring Internet skills. International Journal of Human Computer Interaction (in press)

4. Van Deursen, A.J.A.M., Van Dijk, J.A.G.M.: Using the Internet: Skill-related Problems in Users' Online Behavior. Interacting with Computers, 21 (2009)

5. Merritt, K., Smith, D., Renzo, J.C.D.: An Investigation of Self-Reported Computer Literacy: Is It Reliable? Issues in Information Systems 6(1) (2005)

6. Talja, S.: The Social and Discursive Construction of Computing Skills. Journal of the American Society for Information Science and Technology 56(1), 13-22 (2005)

7. Norris, P.: Digital Divide: Civic Engagement, Information Poverty and the Internet Worldwide, Cambridge (2001)

8. Mossberger, K., Tolbert, C.J., Stansbury, M.: Virtual Inequality: Beyond the Digital Divide. Georgetown University Press, Washington (2003)

9. Warschauer, M.: Technology and Social inclusion: Rethinking the Digital Divide. The MIT Press, Cambridge (2003)

10. Van Dijk, J.A.G.M.: The deepening divide. Inequality in the information society. Sage Publications, London (2005)

11. Van Deursen, A.J.A.M., Van Dijk, J.A.G.M.: Improving digital skills for the use of online public information and services. Government Information Quarterly 26, 333-340 (2009)

12. Zuurmond, A.: In Verweij: Bijscholen maar hoe! Digitaal Bestuur Maart 2009 (2009)

\section{Appendix}

Assignment 1. (max. 6 minutes) - Operational Internet skills

- $\quad$ Task 1.1: Go to the website of the CBR (www.cbr.nl).

- Task 1.2: Click on the link 'Motor' in the menu on the left. Click on the subject 'Motor and scooter', placed in the column 'Brochures.'

- Task 1.3: Open the brochure 'Motor and scooter.' Save the brochure in the folder 'CBR' in My Documents. Close the brochure.

- Task 1.4: Add the homepage to the Favorites (or bookmarks). 
Assignment 2. (max. 5 minutes) - Operational Internet skills.

- Task 2.1: Go to the website of Marktplaats (www.marktplaats.nl). Click the link 'Uitgebreid zoeken.'

- Task 2.2: Complete the fields using the information given.

- Task 2.3: Save the logo of Marktplaats in the upper left corner on the desktop of the computer.

Assignment 3. (max. 8 minutes) - Formal Internet skills.

- Task 3.1: Go to the website of the ANWB (www.anwb.nl). Follow the options Car / Sell / Selling Occasion. Choose the option: 'Selling my car via Auto Trader.'

- Task 3.2: In both windows, go to the homepage of the site opened. Go to the homepage of the Autotrader website in the new window. Go to the homepage of the ANWB in the old window.

Assignment 4. (max. 8 minutes) - Formal Internet skills.

Imagine that you just moved to Nijmegen. You would like to look up the physical office addresses of the following organizations: IB-Groep and UWV.

Assignment 5. T-mobile (max. 10 minutes) - Information Internet skills.

Imagine... 8 months ago you subscribed to a mobile telephone contract with $\mathrm{T}$ mobile. Now you would like to take advantage of the new T-mobile iPhone offer. Answer the following question, using the T-mobile website (www.t-mobile.nl): Is it possible to subscribe to a T-mobile iPhone contract as a continuation of your current subscription?

Assignment 6. Salary (max. $12 \mathrm{~min}$ ) - Information Internet skills.

Imagine that you are 25 years old. In between September 1st and December 30th you had a full-time job in a factory $(40 \mathrm{~h} /$ week). Your wage was 1275 euro gross every month. This was not much. Use a search engine (e.g., www.google.nl or the one you use at home) to find out whether you were entitled to a higher salary during this period. (Yes, because the salary was lower than euro./No, because the salary was higher than _ euro).

Assignment 7. Salary (max. $12 \mathrm{~min}$ ) - Strategic Internet skills.

When your employer paid you too little, what financial recourse do you have can you then personally obtain? Sort this out using the Internet.

Assignment 8. Travelling (max. 25 minutes) - Strategic Internet skills.

Imagine... from March the 7th through the13th of next year you are going on a trip to London with your partner. You would like to book two tickets from a nearby airport (in the Netherlands or just across the border) and a hotel in the centre of London. Find out how much this would cost using the Internet, aiming to identify the cheapest options. Consider flight, hotel and travel expenses to and from the airport in London. 